\title{
Collagen Supplements: Benefits, Uses and Side Effects
}

\author{
Jo Ann Summitt Marrs ${ }^{1 *}$ and Ashley Marrs Strickland ${ }^{2}$ \\ ${ }^{1}$ College of Nursing, East Tennessee State University, USA \\ ${ }^{2}$ Northeast State Community College, USA
}

*Corresponding author: Jo-Ann Summitt Marrs, College of Nursing, East Tennessee

State University, USA.

Received Date: July 23, 2020

Published Date: September 10, 2020

\section{Opinion}

Collagen is a major component of connective tissue making up the structure of tendons, ligaments, skin, and muscles [1]. It is the most abundant protein in the extracellular matrix and has a characteristic triple helix of three polypeptide chains [2].

There have been 28 genetically distinct collagen types described. The following types of collagen are associated with bones (I, V), cartilage (II, XI, VI, X, IX, and XX) and dermis/skin (I, III, VI, VII, XIV, XVII, XX, and XIII) and represent the types that are most targeted for supplementation. In a research study by Asopa $V$, et al. [3] they found that adult cartilage synthesis occurred infrequently with type II collagen in comparison to young cartilage. In fact, precollagen levels were 10 -fold less in adults. There is a growing body of evidence to suggest that collagen supplementation can improve skin, lessen arthritis symptoms and promote wound healing. This article will briefly explore some of those studies.

\section{Skin and Wound Healing}

Due to the synergistic effects of chronological and photoaging, hormonal, and environmental factors the appearance of the skin and integrity gets worse with age. The loss of connective tissue in the skin results in decreased elasticity, loss of skin tone, and progressive deepening of facial creases and wrinkles. The healthy appearance of the skin depends upon a sufficient supply of essential nutrients. Collagen supplementation has been found in numerous research studies to be effective in reducing wrinkles and promoting wound healing [4-9].

\section{Arthritis}

Osteoarthritis affects millions of people worldwide. The protective cartilage near the ends of the bones wear down over time causing pain, stiffness, tenderness, loss of flexibility, grating sensations, and swelling. It mainly affects the hands, knees, hips, and spine [10].

A multitude of research studies [11-18] have shown Collagen to be instrumental in reducing pain, diminishing synovial inflammation and fibrotic response, re-modelling synovial membrane and improving quality of life. Collagen hydrolysate is absorbed intestinally and accumulates in the cartilage. There is causes a significant increase in the synthesis of extracellular matrix macromolecules by chondrocytes which produces a positive outcome.

\section{Side Effects}

Generally considered safe, the side effects of collagen supplements are generally mild and include diarrhea, heaviness in the stomach, and rashes [19]. While all collagen products for sale have been found to contain collagen there have been reported high levels of cadmium, a toxic heavy metal [20]. Fortunately, in 2016 the Food and Drug Administration prohibited the use of cows in dietary supplements to avoid bovine spongiform encephalopathy or mad cow's disease. Gelatin was exempted [20].

\section{Recommendations}

When purchasing collagen supplements buy those that contain all five types of collagen (I, II, III, V and X), those that are nonGMO (grass fed, hormone free and cruelty free sources) and hydrolyzed for absorption capsules. [19]. Finally ensure that there is a certificate of analysis with a label like NSF or USP [20,21].

\section{Acknowledgement}

None. 


\section{Conflict of Interest}

Author declare no conflict of interest.

\section{References}

1. Mayo Clinic (2020) Osteoarthritis.

2. Gelse K, Poschl E, Aigner T (2003) Collagen supplements: Benefits, uses, and side effects. Advanced Drug Delivery Reviews 55: 1531-1546.

3. Asopa V, Vincent T, Saklatvala J (2020) The Effects of Age and Cell Isolation on Collagen II Synthesis by Articular Chondrocytes: Evidence for Transcriptional and Posttranscriptional Regulation. Biomed Res Int 2020: 4060135.

4. Proksch E, Schunck M, Oesser S (2020) Positive effect of fish-derived bioactive collagen peptides on skin health. Nutrafoods 1: 127-133.

5. Borumand M, Sibilia S (2015) Effects of a nutritional supplement containing collagen peptides on skin elasticity, hydration, and wrinkles. Journal of Medical Nutrition and Nutraceuticals, 4(1): 47-53.

6. Proksch E, Schunck M, Zague V, Segger D, Degwert J, et al. (2014) Oral intake of specific bioactive collagen peptides reduce skin wrinkles and increase dermal matrix synthesis. Skin Pharmacol Physiol 27(3): 113119.

7. Choi F, Sung C, juhasz M, Mesinkovsk A (2019) Oral collagen supplementation: A systematic review of dermatological applications. Drugs Dermatol 18(1): 9-16.

8. Choi SY, Ko EJ, Lee YH, Kim BG, Shin HJ, et al. (2014) Effects of collagen tripeptide supplement on skin properties: A prospective, randomized, controlled study. J Cosmet Laser Therapy 16(3): 132-137.

9. Zhang Z, Wang J, Ding Y, Dai X, Li Y (2011) Beneficial effects of collagen hydrolysate: A review on recent developments. Sci. Food Agric 91(12): 2173-2179.

10. Landewe RBM, Geusens P, Van der Heijde D, Boers M, Van der Linden S, et al. (2006) Arthritis instantaneously causes collagen type I and type II degradation in patients with early rheumatoid arthritis, a longitudinal analysis. Ann Rheum Dis 651(1): 40-44.

11. Purgdellwol J, Berenger C, Fernandez M, Millan J, Vidal C, et al. (2019) Effectiveness of a dietary supplement containing hydrolyzed collagen, chrondroitin sulfate and Glucosamine in pain reduction and functional capacity in osteoarthritis patients. J Diet Suppl 16(4): 379-389

12. Bello A, Oesser S (2006) Collagen hydrolysate for the treatment of osteoarthritis and other joint disorders: A review of the literature. Curr Med Res Opin 22(11): 2221-2232.

13. Kumar S, Sugihara F, Suzuki K, Inorie N, Venkateswarathirukumara (2015) A double-blind, placebo-controlled, randomized clinical study on the effectiveness of collagen peptide on osteoarthritis. J Sci Food Agric 95(4): 702-707.

14. Liu X, Machado G, Eyles JP, Ravi V, Hunter D (2018) Dietary supplements for treating osteoarthritis: A systematic review and meta-analysis. Br J Sports Med 52(3): 167-175.

15. Atayda S, Velosa A, Calanozi S, Filho A, Antonangeloa L, et al. (2010) Collagen V-induced nasal tolerance downregulates pulmonary collagen mRNA gene and TGF-beta expression in experimental systemic sclerosis. Respir Res 11(1): 1.

16. Choy E, Farboud A (2011) Serological investigation of IgG levels and subclasses in rheumatoid arthritis patients following ingestion of bovine type II collagen: Results of a double-blind, randomized controlled trial. Clin Rheumatol 302(2): 193-199.

17. Garcia-Coronoda J, Martinez-Olvera L, Elizondo-Omana R, Acosta-Olivo C, Vilchez-Cavazos F, et al. (2019) Effect of collagen supplementation onosteoarthritis symptoms: A meta-analysis of randomized placebocontrolled trials. Int Orthop 43(3): 531-538.

18. Lugo JP, Saiyed ZM, Lane NE (2016) Efficacy and tolerability of an undenatured type II collagen supplement in modulating knee osteoarthritis symptoms: A multicenter randomized, double-blind, placebo-controlled study. Nutr J 15: 14.

19. Fletcher J (2019) What to know about collagen supplements. Medical News Today.

20. Nazario B (2020) Collagen: 'Foundation of Youth' or Edible Hoax? Web MD Health News.

21. Myllyharju J, Kivirikko K (2001) Collagens and collagen-related diseases. Ann Med 33(1): 7-21. 